\title{
Effect of Eating Habits on Oral Health among Junior High Students in the Cape Coast Metropolis
}

\author{
Philip N. Gorleku ${ }^{1}$, Jacob Setorglo ${ }^{2}$, Oxana Gorleku ${ }^{3}$, Klenam Dzefi-Tettey ${ }^{4}$, Emmanuel K. Edzie ${ }^{1}$, \\ Albert D. Piersson ${ }^{5}$ Richard Antwi ${ }^{6}$
}

${ }^{1}$ Department of Medical Imaging, School of Medical Sciences, College of Health and Allied Sciences, University of Cape Coast, Cape Coast, Ghana.

P.M.B University of cape Coast, Cape Coast, Ghana; pgorleku@ucc.edu.gh

${ }^{2}$ Department of Clinical Nutrition \& Dietetics, School of Allied Health Sciences, College of Health and Allied Sciences, University of Cape Coast, Cape Coast, Ghana

P.M.B University of cape Coast, Cape Coast, Ghana; j.setorglo@uccsms.edu.gh

${ }^{3}$ University Dental Unit, University Health Services, University of Cape Coats.

P.M.B University of cape Coast, Cape Coast, Ghana; oxana-gorleku@ucc.edu.gh

${ }^{4}$ Department of Radiology, Korle-Bu Teaching Hospital, Accra, Ghana. PMB, Accra Ghana; k.dzefitettey@kbth.gov.gh

${ }^{5}$ Department of Imaging Technology \& Sonography, School of Allied Health Sciences, College of Health and Allied Sciences, University of Cape Coast, Cape Coast, Ghana.

P.M.B University of cape Coast, Cape Coast, Ghana; albert.piersson@ucc.edu.gh

${ }^{6}$ Department of Medical Laboratory Science, University of Cape Coast. P.M.B University of cape Coast, Cape Coast, Ghana; richant4@gmail.com

Corresponding Author: Philip N. Gorleku: pgorleku@ucc.edu.gh

Received 19 November 2019;

Accepted 12 December 2019;

Published 15 December 2019

\begin{abstract}
The effect of eating habits on the oral health of 200 students at University Junior High School was assessed using cross-sectional survey. $51.8 \%$ of the respondent perceived they have good oral health and $41.7 \%$ had never had any dental condition in the last 6 months. However, there was prevalence of $58.2 \%$ dental conditions among the respondents. $69.3 \%$ had no difficulty brushing the teeth and $56.8 \%$ had no difficulty in eating as a result of dental problem. As such, $77 \%$ of the respondents never visited the dentist in the past five years. The oral health practices among the respondents were good as $61.4 \%$ responded they brush their teeth at least twice a day. The participants generally had bad eating habits as $56.1 \%, 33.6 \%$ and $50 \%$, respectively take fizzy drinks, eat sweets and biscuits with other pastries for more than 3 times in a week. $41.5 \%$ had a scores $\leq 15.0$ on total eating habit indicating good eating habits and $52.0 \%$ had scores $\geq 16.0$, indicating bad eating habits. This accounted for $58.2 \%$ having various dental conditions. Therefore, there is the need for an oral health promotion programme to increase awareness of good oral health practices and good eating/snacking habits among the students.
\end{abstract}

Keywords: Oral Health, Eating Habits, Oral Hygiene, Health promotion.

\section{Introduction}

Oral health is an essential part of general health and plays a major role in a child's life. According to the World Health Organization (WHO), oral health is the state of being free from mouth and facial pain, oral and throat neoplasms, oral infections, gum or periodontal diseases, tooth loss, tooth decay and other diseases. Dental problem in children may be the presence of one or more decayed, missing, or filled tooth surfaces in any primary tooth in a child. Dental Problems impose significant threats to the psychological, physical and social well-being of the child as dental problem and subsequent tooth loss may result in difficulty in eating, speaking, sleeping and socializing $^{[1]}$. Risk factors for oral diseases include unhealthy eating habits or diet, tobacco use, harmful alcohol use, and poor oral hygiene. The limited accessibility to oral health services has also been implicated in various regions of the world, particularly in 
Africa. Data from The WHO Oral Health Programme suggests that the dentist to population ratio in Africa is approximately 1: 150000 as against about 1: 2000 in most industrialized countries ${ }^{[1,2]}$.

According to data from the Ghana Health Services published in 2012, as at 2011, oral health diseases, specifically dental caries placed 19th on the list of 20 top causes of outpatient morbidity ${ }^{[3]}$. Dental caries cases were recorded as 98,996 out of $25,441,412$ outpatient cases representing $0.4 \%{ }^{[2]}$. The report also indicated that there are 38 dental technicians/therapists in the Central region of Ghana (where this study took place) out of a total of 513 in the whole of Ghana representing about $7.4 \%$. Considering the population of Ghana being around 30 million, the presence of 513 dental technicians/therapists represents a dentist to a population ratio of approximately 1:56500. It can also be observed that the presence of oral health services is concentrated in the urban areas.

A study on the oral health status of peri-urban schoolchildren in Accra, Ghana by Bruce et al ${ }^{[4,5,6,7]}$ in 2002 indicated that plaque scores ranged from $78.9 \%$ in $4-5$-year olds to a high of $97 \%$ in $6-$ year olds with older groups occupying intermediate levels. The proportion with calculus ranged with a low of $40 \%$ in the 4-5-year olds to a high of $67 \%$ in the $13-16$-year olds ${ }^{[3]}$. Some children are unable to care for their teeth and therefore mostly depend on their parents ${ }^{[4]}$. Particularly, mothers are the role models for developing good oral health habit during the early years of child's life and he/she acquires the early childhood habits and routines from the mother. Hence, beginning with basic good oral health habits is vital to establish appropriate dental norms that would be part of the adult life. Mothers teach their children proper hygiene skills, dietary habits and healthy practices ${ }^{[5]}$. Literature reports that a child's oral health and oral health-related habits is mostly dependent on the mother's oral health awareness ${ }^{[8,9,10]}$. Analysing the trends of dental pathologies seen at the University of Cape Coast dental clinic and the subsequent results of the dental imaging thereof, it was imperative to study the eating habits of these cohort of children. Also, in the Central region of Ghana, to the best of our knowledge there has been no study exploring the effect of the eating habits on the oral health of school children. The University of Cape Coast junior high school was chosen as most of the pupils are predominantly children of lecturers and the middle class. That is to say children of relatively very educated parents. Therefore, this study seeks to determine the effect of the eating habits of these junior high school pupils (ages between 9-19 years) on their oral or dental health in general and make recommendations thereof. ${ }^{[11,12,13,14]}$

\section{Methodology}

The aim of this study was to assess the effect of eating habits on oral health of school children in the University Junior High School in Cape Coast.

\section{Study Area}

The Study was conducted on the University of Cape Coast campus specifically at the University Junior High School in Cape Coast, in the Central region of Ghana. The school has a population of about 400 students with staff strength of 60 teaching and non-teaching staff.

\section{Study Design}

The study was a cross-sectional survey and was conducted from November 2018 to May 2019. Questionnaires were administered to participants to assess their eating habits and their oral hygiene practices. Total eating habits scores, Total effect scores and Total oral hygiene practice scores were calculated to determine the effect of the eating habits and the oral hygiene practices on the oral health of the participants. With the help of a Dental Surgeon at the University Dental Clinic the oral health status was diligently analysed.

\section{Data Collection Technique and Tools}

Modified World Health Organization oral health questionnaires were administered to participants to assess their eating habits, oral hygiene practices, and the frequency of dental visit. Modified WHO oral assessment forms were used to assess the oral health of participants and Total eating habits scores, Total effect scores and Total oral hygiene practice scores were calculated to assess the effect of the eating habits and the oral hygiene practices on the oral health of the participants.

\section{Study Variables}

The study variables include the demographic features of the participants such as sex and age of participants. The variables also include the presence of dental caries, swollen/bleeding gums, and other dental conditions. Other variables are the diet and frequency of the diet of students, and oral hygiene practices.

\section{Sampling Technique and Sample Size}

A simple random sampling of participants was employed and 200 schoolchildren in the University Junior High School were sampled out of a population of 400 students with $95 \%$ confidence level and a 0.05 margin of error.

\section{Data Analysis}

The data obtained from the study was analysed using IBM Statistical Package for Social Sciences version 25 and the results presented in the form of bar charts, graphs and tables.

\section{Ethical Considerations}

The study was conducted pursuant to the ethical clearance from the Institutional Review Board of the University of Cape Coast and the University Hospital (Dental Clinic). Written informed consent was sought and obtained from study participants and the school authorities. Thorough explanation and the objective of the study was given to each study participant. The participants were assured of confidentiality of their data. There were no measures to compel participants to participate in this study.

\section{Results}

\section{Socio-demographic Characteristics}

The total sample population was 200 which comprises of 90 (45\%) males and 110 (55) females as shown in Fig. 1 with ages between 9 years and 19 years (see Fig. 2). The mean age of the sample was $13.1 \pm 1.5$ years old and the modal age was 14.0 years old. The results showed that majority of the respondents' parents has higher tertiary education and as such, they are in better position to practice good oral health. 144 students representing $73.1 \%$ indicated that their fathers have higher University education as against 136 $(69.7 \%)$ of mothers have higher tertiary education. The results also showed that $13(6.60 \%)$ students indicated that their fathers have had no formal education while $10(5.13 \%)$ students indicated that their mothers have had no formal education (see Fig. 3). 


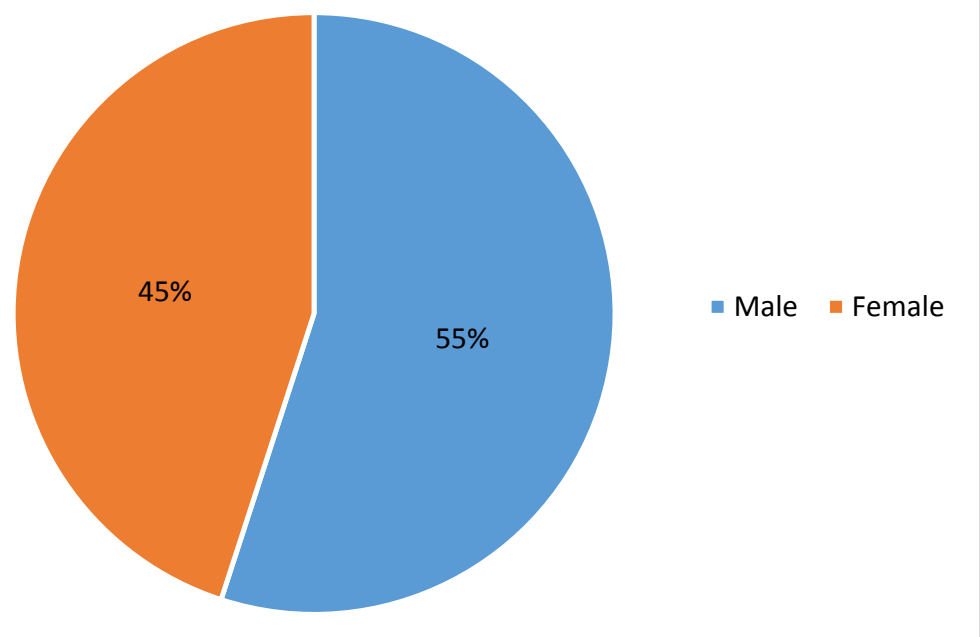

Figure 1: Gender Distribution of Participants

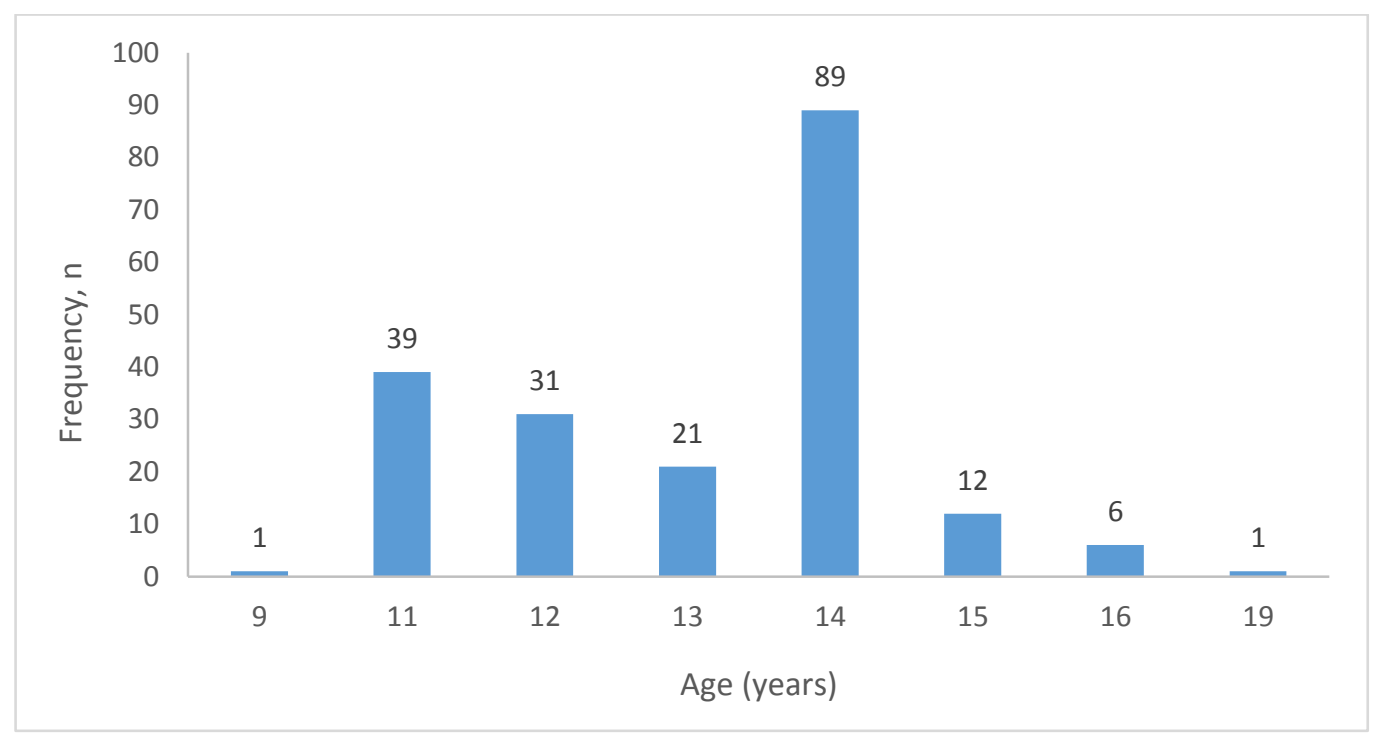

Figure 2: Age Distribution of Participants

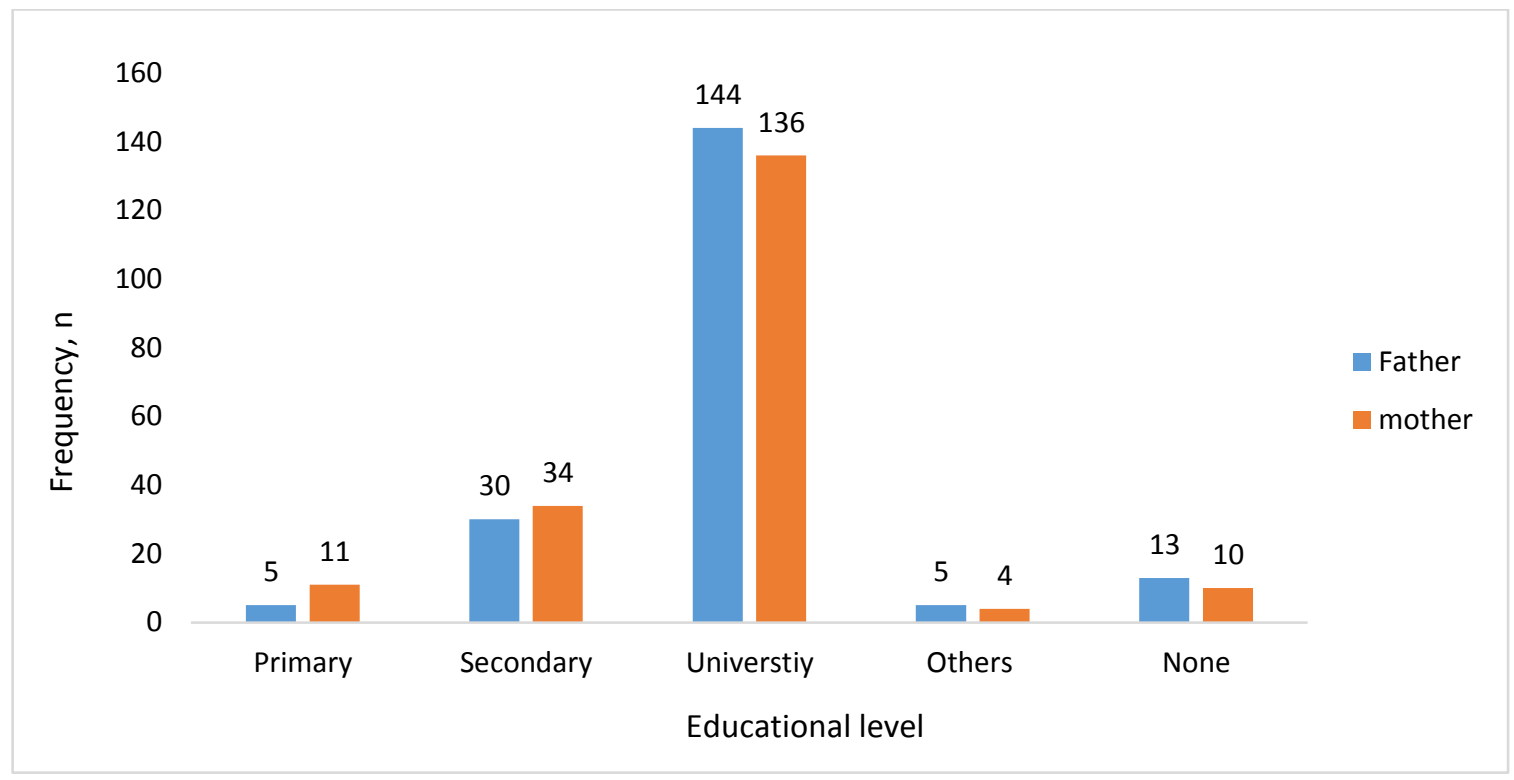

Figure 3: Education status of respondent's parents

\section{Dental Health Perception}

Respondents generally perceived their dental health to be good as shown in Table $1.100(50 \%)$ respondents perceived their dental health to be good, 57 (28.5\%) perceived their dental health to be very good whereas $9(4.5 \%)$ perceived their dental health to be poor. $2(1 \%)$ respondents perceived their dental health to be very poor and $4(2 \%)$ students failed to provide a response 
On whether the respondents had had any dental conditions in the last 6 months, $83(41.7 \%)$ had no occurrence of dental conditions in the past months. 29 (14.6\%) reported having a toothache in the last 6 months, while 7 (3.5\%) reported that they had more than one dental conditions in the last 6 months.

With regards to the cleaning of their teeth, the respondents generally had very little or no difficulty cleaning their teeth and had no problems with their mouth or teeth. The results showed 137 $(68.5 \%)$ respondents who claimed they have never had any difficulty cleaning their teeth due to problems with their mouth or teeth in the past 6 months, $52(26.0 \%)$ respondents claimed they sometimes had difficulty cleaning their teeth due to problems with their mouth or teeth in the past 6 months.

Again, with regards to challenge with eating, 113 (56.8\%) respondents claimed they have never had difficulty eating due to problems with their mouth or teeth and $79(39.7 \%)$ reported of sometimes having difficulty eating due to problems with their mouth or teeth. The general response to how comfortable or otherwise in relaxing, $172(86.4 \%)$ respondents claimed they have never had any difficulty relaxing (including sleeping) due to problems with their mouth or teeth and $22(11.0 \%)$ respondents claimed they sometimes had difficulty relaxing (including sleeping) secondary to difficulties with their mouth or teeth. Only 2 respondents claimed of always having difficulty in relaxing or sleeping due to problems with their teeth.

Table 1: Dental health perception of respondents

\begin{tabular}{|c|c|c|}
\hline STATEMENT & Frequency & Percentage \\
\hline \multicolumn{3}{|l|}{$\begin{array}{l}\text { How would you describe the health } \\
\text { of your teeth and gums? }\end{array}$} \\
\hline Very good & 57 & 28.6 \\
\hline Good & 100 & 51.8 \\
\hline Fair & 28 & 14.1 \\
\hline Poor & 9 & 4.5 \\
\hline Very poor & 2 & 1.0 \\
\hline \multicolumn{3}{|l|}{$\begin{array}{l}\text { Have you had any dental conditions } \\
\text { in the last } 6 \text { months? }\end{array}$} \\
\hline Toothache & 29 & 14.6 \\
\hline Sensitive tooth & 28 & 14.1 \\
\hline Swollen or bleeding gum & 18 & 9.0 \\
\hline Broken tooth & 16 & 8.0 \\
\hline Bad breath & 17 & 8.5 \\
\hline Mouth ulcers & 1 & 0.5 \\
\hline More than one & 7 & 3.5 \\
\hline None & 83 & 41.7 \\
\hline \multicolumn{3}{|l|}{$\begin{array}{l}\text { In the past } 6 \text { months, have you had } \\
\text { difficulty cleaning your teeth due to } \\
\text { problems in your mouth or with } \\
\text { your teeth? }\end{array}$} \\
\hline Never & 138 & 69.3 \\
\hline Sometimes & 52 & 26.1 \\
\hline Often & 7 & 3.5 \\
\hline Always & 2 & 1.0 \\
\hline \multicolumn{3}{|l|}{$\begin{array}{l}\text { In the past } 6 \text { months, have you had } \\
\text { difficulty in eating due to } \\
\text { problems in mouth or with your } \\
\text { teeth? }\end{array}$} \\
\hline Never & 113 & 56.8 \\
\hline Sometimes & 79 & 39.7 \\
\hline Often & 3 & 1.5 \\
\hline Always & 4 & 2.0 \\
\hline In the past 6 months, have you had & & \\
\hline
\end{tabular}

\begin{tabular}{|l|c|c|}
\hline $\begin{array}{l}\text { difficulty in relaxing } \\
\text { (including sleeping) due to } \\
\text { problems in your teeth and mouth? }\end{array}$ & 172 & \\
\hline Never & 22 & 11.1 \\
\hline Sometimes & 2 & 1.0 \\
\hline Often & 3 & 1.5 \\
\hline Always & & \\
\hline
\end{tabular}

\section{Eating/Dietary Habits of Participants}

Table 2 shows the eating habits of respondents. We had 44 respondents out of 196 representing $22.4 \%$ claimed to eat cakes, biscuits and other pastries 6 or more times in a week. 60 respondents $(30.6 \%)$ claimed to eat cakes, biscuits and other pastries 1-2 times a week, and $23(11.7 \%)$ respondents reported that they rarely or never ate cakes, biscuits and other pastries.

On the average, majority (26.5\%) reported of eating sweets (toffees) or chocolate $1-2$ times a week while 32 (16.3\%) respondents said they ate sweets (toffees) or chocolate 6 or more times a week while $40(20.4 \%)$ respondents claimed they rarely or never ate sweets or chocolate in a week. 34 and 38 respondents ate sweets or chocolates $3-5$ times a week and less than a week respectively. 4 students did not respond to the questions.

Generally, there was a high frequency of consumption of fizzy drinks as majority (31.6\%) of the respondents said that on the average, they consumed fizzy or "soft" drinks 6 or more times in a week while $48(24.5 \%)$ respondents claimed to consume fizzy drinks 3-5 times in a week as well as 46 (23.5) respondents reported of taking fizzy drinks $1-2$ times a week. However, 10 (5.1\%) respondents claimed they rarely or never consumed fizzy drinks. 4 students failed to respond to the question.

The consumption of fruits was also generally high among the respondents with the same $56(28.3 \%)$ respondents each claimed they consumed fruits 6 or more times a week and $3-5$ times a week respectively. A total of $51(25.8 \%)$ claimed they consumed fruits 1 - 2 times a week while $16.2 \%$ respondents claimed they eat fruits less than once a week. However, only 3 respondents said they rarely or never consumed fruits in a week with 2 students failing to respond to the question.

\section{Table 2: Eating habits of respondents}

\begin{tabular}{|l|c|c|}
\hline Statement & Frequency & Percentage \\
\hline $\begin{array}{l}\text { How often, on the average do you } \\
\text { eat cakes, biscuits and other } \\
\text { pastries? }\end{array}$ & & \\
\hline 6 or more times a week & 44 & 22.4 \\
\hline $3-5$ times a week & 54 & 27.6 \\
\hline $1-2$ times a week & 60 & 30.6 \\
\hline Less than once a week & 15 & 7.7 \\
\hline Rarely or never & 23 & 11.7 \\
\hline $\begin{array}{l}\text { How often, on the average do you } \\
\text { eat sweets (toffees) or chocolates? }\end{array}$ & & \\
\hline 6 or more times a week & 32 & 16.3 \\
\hline $3-5$ times a week & 34 & 17.3 \\
\hline $1-2$ times a week & 32 & 26.5 \\
\hline Less than once a week & 40 & 19.4 \\
\hline Rarely or never & & 20.4 \\
\hline $\begin{array}{l}\text { How often, on the average do you } \\
\text { take fizzy drinks or soft drinks } \\
\text { (Coke, Fanta, Malt, Kalyppo etc.)? }\end{array}$ & 62 & \\
\hline 6 or more times a week & 48 & 24.5 \\
\hline $3-5$ times a week & 46 & 23.5 \\
\hline $1-2$ times a week & 30 & 15.3 \\
\hline Less than once a week & 10 & 5.1 \\
\hline Rarely or never & & \\
\hline $\begin{array}{l}\text { How often, on the average do you } \\
\text { eat fruits? }\end{array}$ & & \\
\hline
\end{tabular}




\begin{tabular}{|l|c|c|}
\hline 6 or more times a week & 56 & 28.3 \\
\hline $3-5$ times a week & 56 & 28.3 \\
\hline $1-2$ times a week & 51 & 25.8 \\
\hline Less than once a week & 32 & 16.2 \\
\hline Rarely or never & 3 & 1.5 \\
\hline
\end{tabular}

\section{Oral Hygiene/Health Practices of Respondents}

Majority (151) of the respondents had never visited the dentist within the last 5 years (as shown in Table 3). However, 23 representing $11.7 \%$ had visited the dentist once in the last 5 years while 10 respondents reported of having visited the dentist $1-2$ times in the last five years. A total of $6(3,1 \%)$ students each claimed they had visited the dentist $3-5$ times and 6 times or more respectively.

The results further showed that, a majority (61.4\%) of students brush their teeth twice a day followed by $33.5 \%$ who brush their teeth once a day and $2.5 \%$ of the respondents said they brush their teeth $3-5$ times in a day. Also 4 respondents stated they brushed their teeth 6 or more times in a day with only one respondent who claimed he/she has never brushed the teeth. We had 3 students failing to respond to the question.

Analysis of the material respondents used in cleaning their teeth showed $181(91.4 \%)$ respondents use toothbrush and toothpaste with $3(1.5 \%)$ respondents claiming they use charcoal in cleaning their teeth while a respondent each claimed to use dental gum and others respectively. Furthermore, 12 (6.1\%) respondents said they use more than one of the materials provided. 2 students failed to respond to the question.

On the frequency of use of oral hygiene product, 78 (39.2\%) respondents claimed they rarely or never use products such as mouth wash, $71(35.7 \%)$ respondents claimed they sometimes use products such as mouth wash and 24 respondents claimed that they use products such as mouth wash two times a day with only $4 \%$ who use the product 3 times a day.

It was interesting to note that $51 \%$ of the respondents had never used dental floss before with only $3.6 \%$ who stated they always use dental floss in cleaning their teeth. A total of 70 respondents representing $35.7 \%$ said they sometimes use dental floss in cleaning their teeth.

Regarding the wash of the mouth after eating, we had 93 $(46.5 \%)$ respondents who said they sometimes rinse their mouth with water after a meal as against $46(23.1 \%)$ respondents who had never rinsed their mouth with water after meals and on the contrary, $32(16.1 \%)$ respondents claimed they always rinse their mouths with water after a meal.

Table 3: Oral health practice by respondents

\begin{tabular}{|l|c|c|}
\hline Statement & Frequency & Percentage \\
\hline $\begin{array}{l}\text { How often have you visited the } \\
\text { dentist in the last 5 years? }\end{array}$ & & \\
\hline 6 or more times & 6 & 3.1 \\
\hline $3-5$ times & 6 & 3.1 \\
\hline $1-2$ times & 10 & 5.1 \\
\hline Once & 151 & 11.7 \\
\hline Never & & 77.0 \\
\hline $\begin{array}{l}\text { How often do you brush your teeth } \\
\text { in a day? }\end{array}$ & 4 & \\
\hline 6 or more times & 5 & 2.0 \\
\hline $3-5$ times & 121 & 61.4 \\
\hline $1-2$ times & 66 & 33.5 \\
\hline Once & 1 & 0.5 \\
\hline Never & & \\
\hline $\begin{array}{l}\text { What do you use to clean your } \\
\text { teeth? }\end{array}$ & 3 & 1.5 \\
\hline Charcoal & 181 & 91.4 \\
\hline Toothbrush and toothpaste & & \\
\hline
\end{tabular}

\begin{tabular}{|l|c|c|}
\hline Dental gum & 1 & 0.5 \\
\hline Others & 1 & 0.5 \\
\hline More than one & 12 & 6.1 \\
\hline $\begin{array}{l}\text { How often do you use other oral } \\
\text { hygiene products such as mouth } \\
\text { wash? }\end{array}$ & & \\
\hline 3 times a day & 8 & 4.0 \\
\hline 2 times a day & 24 & 12.1 \\
\hline Once a day & 18 & 9.0 \\
\hline Sometimes & 71 & 35.7 \\
\hline Rarely or never & 78 & 39.2 \\
\hline $\begin{array}{l}\text { How often do you use dental floss } \\
\text { to clean your teeth? }\end{array}$ & 100 & 51.0 \\
\hline Never & 70 & 35.7 \\
\hline Sometimes & 19 & 9.7 \\
\hline Often & 7 & 3.6 \\
\hline Always & & \\
\hline $\begin{array}{l}\text { Do you rinse your mouth with water } \\
\text { after meals? }\end{array}$ & 46 & 23.1 \\
\hline Never & 93 & 46.7 \\
\hline Sometimes & 28 & 14.1 \\
\hline Often & 32 & 16.1 \\
\hline Always & & \\
\hline
\end{tabular}

Total Score for Eating Habits, Oral Hygiene Practice and Problems with the Teeth

The total eating habit scores was computed from 5 variables including the frequency of eating cakes, biscuits and other pastries in a week, the frequency of eating toffees and chocolate, the frequency of consuming fizzy drinks, the frequency of consuming sugar with other beverages, and the frequency of eating Ice cream. The mean total eating habit score was $16.13 \pm 4.09$ and the modal score was 17.4 participants representing $2 \%$ had a total score of 25,1 participant representing $0.5 \%$ had a total score of 5, while 20 (10\%) participants had a total score of 17 . A scale of $5-25$ was used in the scoring with scores of less than/equal to $15.0(\leq 15.0)$ indicating good eating habits, while scores of greater than or equal to $16.0(\geq 16.0)$ indicating bad eating habits. A total of 83 participants representing $41.5 \%$ had scores $\leq 15.0$, thus indicating good eating habits and 104 participants representing $52.0 \%$ had scores $\geq 16.0$, indicating bad eating habits. 13 participants did not respond.

Also, the total oral hygiene practice by the respondents was computed from 5 variables including frequency of visits to the dentist in the last 5 years, frequency of teeth brushing in a day, frequency of using oral hygiene products such as mouthwash, frequency of rinsing the mouth after a meal, and the frequency of flossing. The mean score was $17.89 \pm 2.45$ and the modal score was 19.0. We had 8 participants representing $4 \%$ had a total score of 22.0, 1 participant representing $0.5 \%$ had a total score of 9 , while 36 participants representing $18.0 \%$ had a total score of 19.0 . The total scores were on a scale of $9-22$, with scores of less than/ equal to $15.5(\leq 15.5)$ indicating good oral health/hygiene practices, while scores of greater than or equal to $15.51(\geq 15.51)$ indicating bad oral health/hygiene practices. A total of 28 participants representing $14.0 \%$ had scores $\leq 15.5$, thus indicating good oral hygiene practices and 157 participants representing $78.5 \%$ had scores $\geq 15.51$, indicating bad oral hygiene practices with 15 participants failing to respond.

Furthermore, the total effect (problems with the teeth) scores were computed from 3 variables including difficulty in cleaning the teeth due to problems with the teeth and mouth, difficulty in eating due to problems with the teeth and mouth, and difficulty in sleeping/relaxing due to problems with the teeth and mouth. The mean score was $4.02 \pm 1.33$ and the modal score was 3.0. We had 91 participants representing $45.5 \%$ who had a total score of 3,1 
participant representing $0.5 \%$ had a total score of 12 , and 17 participants representing $8.5 \%$ had a total score of 6 . The scores were on a scale of $3-12$, with scores of less than/equal to 7.5 ( $\leq$ 7.5) indicating low effect of the participant's oral health on their quality of life, while scores of greater than or equal to $7.51(\geq 7.51)$ indicating a high effect of the participant's oral health on their quality of life. A total of 193 participants representing $96.5 \%$ had scores $\leq 7.5$, thus indicating a low effect and 4 participants representing $2.0 \%$ had scores $\geq 7.51$, indicating a high effect. 3 participants did not respond.

\section{Spearman's correlations matrix of dental parameters in the study population}

The relationship between total effect scores and total oral health practice scores was studied using Spearman's correlation. There was a weak positive relationship between total effect scores and total oral health practice scores with rho $=0.052, \mathrm{~N}=183, \mathrm{p}=$ 0.485 with high scores on total oral health practices (bad oral practices) associated with high scores on total effect (High effect).

The relationship between total effect scores and total eating habits scores was also studied using Spearman's correlation. There was a weak positive relationship between total effect scores and total eating habit scores with rho $=0.051, \mathrm{~N}=185, \mathrm{p}=0.491$ with high scores on total eating habits (bad oral practices) associated with high scores on total effect (High effect).

\section{Discussions}

The general perception of dental health in the population was good as $51.8 \%$ of the participants perceived that their dental health was good. This was confirmed by the finding that almost half of the participants (41.7\%) had never had any dental condition including toothache, sensitive tooth, swollen gums, etc in the last 6 months.

The prevalence of dental conditions was $58.2 \%$ among the population, and this is consistent with the prevalence of oral health/dental conditions in Ghana as reported by a study in the Brong Ahafo Region of Ghana which showed a high prevalence of periodontal disease and a low prevalence of tooth decay ${ }^{[9]}$. The effect of these dental conditions on the quality of life of the participants was low/minimal as most of the participants (86.0\%) had never had difficulty relaxing or sleeping due to oral health conditions. Also $56.5 \%$ of the participants had never had difficulty eating due to any dental conditions, and $68.5 \%$ of the participants had never experienced any problems with cleaning their teeth due to oral health conditions.

The consumption of cariogenic foods such as cakes, and biscuits was high, as $68.5 \%$ of the participants reported eating cakes and biscuits $1-6$ times per week. $62 \%$ of the males reported eating cakes and biscuits 1 - 6 times per week, while $76.6 \%$ of the females reported eating cakes and biscuits $1-6$ times per week. The consumption of sweets and chocolate was also high as $59 \%$ of the participants reported eating toffees and chocolate $1-6$ times a week. The consumption of fizzy drinks was also high as $78 \%$ of participants reported consuming fizzy drinks 1 - 6 times a week. However, the consumption of cariogenic snacks is only significant in causing dental conditions when accompanied by poor oral hygiene practices. ${ }^{[15,16]}$

The population generally reported brushing their teeth twice in a day, as $61.4 \%$ of the participants reported brushing their teeth at least twice in a day. This is in contrast with a similar study among peri-urban school children in Accra where $42.0 \%$ of the participants brushed their teeth twice in a day ${ }^{[17,18]}$. The frequency of dental clinic attendance was very low in the population even though the study site was close to a dental facility. $77 \%$ of the participants had never been to the dental clinic in the last 5 years which is in agreement with a similar study among peri-urban school children in Accra where $77.8 \%$ had not been to the dentist/ dental clinic ${ }^{[19,20,21]}$. This could be as a result of the general phobia people have in visiting the Dentist. The use of dental floss among the respondents was fairly poor as $51 \%$ of the population had never used dental floss in cleaning their teeth, which is consistent with a similar study in peri-urban school children in Accra, where the floss use was very poor as $94 \%$ of the study population never used dental floss. The difference could be attributed to the location of the study site of the present study as it is located on a University campus, and most of the school children are from homes with literate parents as the results showed that majority of the respondents' parents had university degree and as such, they are in better position to practice good oral health albeit bad eating habit which is understandable since most of the children can afford and are provided with types of food they wish to eat. The awareness of the parents of the parents about the effects of these cariogenic foods may be low and therefore there is low conscious efforts to steer the children away from these foods. The general affinity for one food or the other can be cultivated and nurtured to affect eating habits. ${ }^{[22]}$

The scoring system that was generated for the total effect, total eating habits and total oral health practices showed that about $52 \%$ of the population had bad eating/snacking habits with majority consuming fizzy drinks, cakes and other cariogenic snacks on daily basis. Also, $78.5 \%$ had bad oral health practices which included not visiting the dentist, not using oral products such as mouthwash etc, although most of the participants brushed their teeth twice in a day. However, the effect of dental conditions on the quality of life of participants was low as $96.5 \%$ of the participants reported of a low effect on their quality of life such as cleaning their teeth, eating and relaxing or sleeping. This could account for why most of them had never been to the dental clinic. The trends can be reversed with conscious and targeted oral health education.

\section{Conclusions and Recommendations}

The oral health of the participants in this study is fairly poor as most of them had had one or more dental conditions in recent times. Also, there is poor oral health practices among the study population as it is evident that there is low patronage of dental health services and the eating/snacking habits of the study population is poor. However, this seems to have very little effect on the quality of life of the participants. Hence, there should be oral health promotion programme by the Directorate of University Health Services in collaboration with junior high school authorities to educate the students on good oral health practices. Also, students should be sensitized on the effect of bad eating/snacking habits on their oral health and their general health, as the consumption of large amounts of snacks contributes to childhood obesity, predisposing them to non-communicable diseases in the future. Furthermore, students should be sensitized on the activities of the dental clinic, so alleviate the fear or negative perception they may have of the dental clinic in order to encourage them to patronize their services. The results of this study can also be shared with parents through the Parent Teacher Association of the school to bring awareness to parents and encouraging them to help promote healthy eating habits for their wards and the positive oral health thereof. Parents also to support their children and disabuse their phobia in the visitation to the dental clinic. Regular dental checkups must therefore be encouraged. 


\section{Limitations of Study}

The study was unable to assess the effect of the socioeconomic differences on oral health practices as most of the participants were in the same socioeconomic class. The study was also unable to assess the oral health status using other indices such as Community Periodontal Index (CPI), Decayed Missing Filled Teeth (DMFT) scores, and Plaque scores.

\section{Data Availability}

The data used to support the findings of this study may be released upon application to the Head of Dental unit, University Health Services of the University of Cape Coast.

Postal Address: P.M.B University post office. Cape Coast, Ghana.

Email: oxana-gorleku@ucc.edu.gh

\section{Conflicts of Interest}

The authors have no competing interests to declare.

\section{Funding Statement}

Nil

\section{Authors' contributions}

PG: Conception, design and drafting of manuscript, revision of manuscript. JS: Data collection and critical revision of content of manuscript. OG: Conception, critical revision of intellectual content and data analysis. KD-T: Data analysis and proof reading. EE: Data Collection and review of manuscript. AP: Data collection and statistical analysis. RA: Data collection. All authors read and approved the final manuscript.

\section{Acknowledgments}

The authors wish to thank the authorities and staff of the University of Cape Coast Junior High School and the entire students for their support during the study.

\section{References}

[1] FDI World Dental Fideration, The Challenge of Oral Disease: A Call for Global Action, 2nd ed., vol. 180, no. 3. Brighton, UK: Mariad Editions, 2015.

[2] Kwon, H. K., Suh, I., Kim, Y. O., Kim, H. J., Nam, C. M., Jun, K. M., \& Kim, H. G. (1997). Relationship between nutritional intake and dental caries experience of junior high students. Yonsei medical journal, 38(2), 101110

[3] Ghana Health service, "The Health Sector in ghana: Facts and Figures," Accra, 2012.

[4] I. Bruce, M. Addo, and T. Ndanu, "Oral health status of peri-urban schoolchildren in Accra, Ghana," Int. Dent. J., vol. 52, pp. 278-282, Sep. 2002.

[5] A. Abiola Adeniyi, O. Eyitope Ogunbodede, O. Sonny Jeboda, and O. Morenike Folayan, "Do maternal factors influence the dental health status of Nigerian pre-school children?," Int. J. Paediatr. Dent., vol. 19, no. 6, pp. 448454, 2009.

[6] B. S. Suresh, T. L. Ravishankar, T. R. Chaitra, A. K. Mohapatra, and V. Gupta, "Mother' s knowledge about pre-school child' s oral health," J. Indian Soc. Pedod. Prev. Dent., vol. 28, no. 4, pp. 282-287, 2010.

[7] M. Al-Zahrani, A. S. Al-Mushayt, M. F. Otaibi, and A. H. Wyne, "Knowledge and attitude of Saudi mothers towards their preschool children's oral health," Pakistan J. Med. Sci., vol. 30, no. 4, 2014.

[8] G. Kumar, D. Singh, M. Jalaluddin, C. L. Dileep, P. Rout, and R. Mohanty, "Oral Health of Pre-School Aged Children in Dhanbad District, Jharkhand, India- A Peek into their Mother's Attitude,” J. Clin. Diagn. Res., vol. 7, pp. 2026-2060, Sep. 2013.

[9] Z. Saied-Moallemi, J. Virtanen, F. Ghofranipour, and H. Murtomaa, "Influence of mothers' oral health knowledge and attitudes on their children's dental health," Eur. Arch. Paediatr. Dent., vol. 9, pp. 79-83, Jul. 2008.

[10] M. I. Houpt, S. Adu-Aryee, and R. M. Grainer, "Dental Survey in the Brong Ahafo of Ghana," Elsevier, vol. 12, no. 12 , p. $1967,1967$.

[11] P. Axelsson and J. Lindhe, "Effect of controlled oral hygiene procedures on caries and periodontal disease in adults: Results after 6 years," J. Clin. Periodontol., vol. 8 , no. 3, pp. 239-248, 1981.

[12] T. A. Ndanu, R. Aryeetey, J. Sackeyfio, G. Otoo, and A. Lartey, "Oral Hygiene Practices and Caries Prevalence among 9-15 Years Old Ghanaian School Children," J. Nutr. Heal. Sci., vol. 1, no. 4, pp. 1-8, 2015.

[13] Kwan, S. Y., Petersen, P. E., Pine, C. M., \& Borutta, A. (2005). Health-promoting 3schools: an opportunity for oral health promotion. Bulletin of the World Health organization, 83, 677-685.

[14] Petersen, P. E., Peng, B., Tai, B., Bian, Z., \& Fan, M. (2004). Effect of a school-based oral health education programme in Wuhan City, Peoples Republic of China. International dental journal, 54(1), 33-41.

[15] Sheiham, A., \& Watt, R. G. (2000). The common risk factor approach: a rational basis for promoting oral health. Community Dentistry and Oral Epidemiology: Commentary, 28(6), 399-406.

[16] Tai, B. J., Jiang, H., Du, M. Q., \& Peng, B. (2009). Assessing the effectiveness of a school-based oral health promotion programme in Yichang City, China. Community dentistry and oral epidemiology, 37(5), 391398.

[17] Vanobbergen, J., Declerck, D., Mwalili, S., \& Martens, L. (2004). The effectiveness of a 6-year oral health education programme for primary schoolchildren. Community dentistry and oral epidemiology, 32(3), 173182.

[18] Dixit, L. P., Shakya, A., Shrestha, M., \& Shrestha, A. (2013). Dental caries prevalence, oral health knowledge and practice among indigenous Chepang school children of Nepal. BMC oral Health, 13(1), 20.

[19] Jiang, H., Petersen, P. E., Peng, B., Tai, B., \& Bian, Z. (2005). Self-assessed dental health, oral health practices, and general health behaviors in Chinese urban adolescents. Acta Odontologica Scandinavica, 63(6), 343-352.

[20] Peng, B., Petersen, P. E., Fan, M. W., \& Tai, B. J. (1997). Oral health status and oral health behaviour of 12-year-old urban schoolchildren in the People's Republic of China. Community Dental Health, 14(4), 238-244. 
[21] Friel, S., Hope, A., Kelleher, C., Comer, S., \& Sadlier, D. (2002). Impact evaluation of an oral health intervention amongst primary school children in Ireland. Health promotion international, 17(2), 119-126.
[22] Jürgensen, N., \& Petersen, P. E. (2009). Oral health and the impact of socio-behavioural factors in a cross sectional survey of 12-year old school children in Laos. BMC oral health, 9(1), 29. 